\title{
Lessons from the Celltech Case: Balancing Knowledge Exploration and Exploitation in Organizational Renewal ${ }^{1}$
}

\author{
Peter McNamara and Charles Baden-Fuller \\ City University Business School, Frobisher Crescent, Barbican, London EC2Y 8HB, UK
}

\begin{abstract}
This article applies the lens of the knowledge exploration/exploitation dilemma to the renewal of Celltech PIc. From a theoretical perspective it has often been argued that as a firm matures, exploitation of current organizational knowledge drives out exploration of new ideas, and that this increases the likelihood of firm failure. This same literature gives few clues as to how balance can be maintained, or decline reversed. Our case study documents the decline of Celltech, its rejuvenation from near bankruptcy in 1990, and its subsequent ability to prosper to become the eighth largest biotech firm in the $E U$ in terms of market capitalization. Through the Celltech case we show empirically that renewal based on exploration is possible even in a firm where exploitation has come to dominate. This case also illustrates how a balance between exploration and exploitation can be maintained for over half a decade, despite the theoretical tendency stated in the literature for exploitation to dominate. We offer insights into the process of maintaining a balance, including reorganization to release internal diversity to stimulate exploration, creation of a common language, and building systems to institutionalize the maintenance of a balance between exploration and exploitation.
\end{abstract}

\section{Introduction}

Can high technology firms renew? The classical view of industry evolution emphasizes the difficulties that firms face in adjusting to new circumstances; cognitive and organizational inertia are often blamed for resistance. Longitudinal studies of renewal usually exclude studies of high technology (such as Baden-Fuller and Stopford, 1994; Pettigrew and Whipp, 1991). The story of Intel (Burgelman and Grove, 1996) is an exception,

\footnotetext{
1 We are grateful for the advice and comments of the Editor and two anonymous $B J M$ reviewers who have helped to shape this work. The article has benefited from the advice and comments of Alison Dean, Madeleine Bateman, Oliviero Roggi and Neil Thomson, all of City University Business School, Professor Robert DiFillipi, visiting professor at CUBS, and Simon Bird. We gratefully acknowledge the assistance of Professor John Howell, of the Department of Chemical Engineering at the University of Bath, who participated in the data
}

but this story stresses the role of serendipity and the accidental nature of the process (Burgelman, 1994).

Here we tell another story, that of Celltech, one of Europe's largest and oldest biotechnology firms, which managed to renew itself under the direction of a new CEO. Celltech pushed back its historic trajectory, an unusual feat. We make no pretence that Celltech is a common story. In its early life, Celltech had two businesses: pure R\&D of novel therapeutic drugs, and a much bigger

collection and write up of the Celltech case study. Earlier versions of this article were presented at the following conferences: the Academy of Management 1998, the Eastern Academy of Management 1997 and the British Academy of Management 1996. In addition we acknowledge the helpful comments of participants at University College Dublin and City University Business School research seminars. We gratefully acknowledge financial support from the Design Council, University College Dublin and Sundridge Park. 
business undertaking specialized contract manufacturing. In this latter area, it developed a leading edge technological capability centred on recombinant DNA and hybridoma technologies (Dodgson, 1991, 1993). It then hit a crisis and unusually shifted its emphasis, diminishing contract manufacturing and greatly expanding and altering its strategic focus towards drug discovery and development in a higher technological space. This was unusual in that it defied the theoretical convention that exploitation of current knowledge tends, over time, to dominate over exploration for new knowledge (Levinthal and March, 1993; March, 1991). Despite the fact that this R\&D investment has yet to yield a drug approved for marketing by regulatory authorities, this strategic shift has resulted in the firm becoming more, rather than less, successful financially. In 1990 Celltech was a privately owned firm near bankruptcy. By February 1999 it had been listed on the London Stock Exchange for six years. It had a market capitalization of $\$ 502$ million, making it the eighth largest independently quoted biotechnology firm in Europe, fifth in the UK (McNamara, 1999).

\section{Theory}

It is widely argued in the literature that a central component of success is the maintenance of a balance of exploration and exploitation ${ }^{2}$ within the firm (Cohen and Levinthal, 1990; Hendry, 1996; Levinthal, 1997; Levinthal and March, 1993). In common with others, March (1991) observed that the maintenance of a balance between exploration and exploitation is 'a primary factor in system survival and prosperity'. Celltech's story, elaborated below, runs counter to the oft stated theoretic proposition in the literature that exploitation tends to dominate over exploration. This logic is summed up by Levinthal and March (1993):

'Exploitation generates clearer, earlier and closer feedback than exploration. It corrects itself sooner and yields more positive returns in the near term. As a result, the primary challenge to sustaining

\footnotetext{
${ }^{2}$ Exploration can be defined as 'the pursuit of new knowledge of things that might come to be known' and exploitation as 'the use and development of things already known' (Levinthal and March, 1993).
}

an optimal mix of exploration and exploitation is the tendency of rapid learners and successful organisations to reduce the resources allocated to exploration.'

In mature organizations exploitation tends to drive out exploration, making renewal based on exploration very difficult. Renewal based on the creation and application of new core capabilities is very difficult (Leonard-Barton, 1995; Peteraf, 1993). The key problem is that the development of core capabilities tends to be path-dependent (Cohen and Levinthal, 1989, 1990, 1994; Collis, 1991; Mahoney, 1995). The initial success of a core capability leads to its growth over time. Success based on the exploitation of that core capability reinforces the behaviours upon which it is based. Over time these behaviours become deeply embedded in the organization. This process of deepening a core capability enables the firm to refine its organizational routines and procedures in knowledge integration to such a point that it knows more than any other firm about how to deliver, efficiently and effectively, value added to a particular market. But as market needs change over time, other knowledge bases may emerge to deliver superior value added. This shift may 'maroon' established 'mature' firms, leaving them with core capabilities that are no longer appropriate (Herriott, Levinthal and March, 1985; Miller, 1993). The resulting rigidities are due to the high switching costs involved in changing core capabilities (Kogut and Zander, 1992); inertia within the organization (Huff, Huff and Thomas, 1992); and the high level of uncertainty (and hence cost) attached to investments in the exploration of new knowledge (Levinthal and March, 1993; March, 1991).

As the firm hits a performance crisis the natural predisposition of employees is to get out of trouble by focusing on doing what they currently do more efficiently. They rely on the core competencies of the past to deliver success once more. Efficiency drives enable the firm to avoid confronting the very difficult realization that its past core competencies are now core rigidities and must be replaced, rather than overhauled. It is very difficult for organizational members to abandon past successful behaviours and explore new knowledge upon which to create new core competencies that better meet the needs of the market.

There is, of course, a literature on corporate restructuring and renewal. The restructuring strand 
is typically understood as refocusing through downsizing of a business unit or the shedding of unprofitable units from a multi-unit firm (Hoskisson and Hitt, 1994; Markides, 1995; Robbins and Pearce, 1992). Celltech had only two divisions, reducing the relevance of these proscriptions. Moreover, its renewal was based on revitalizing the smaller, unprofitable research division not the profitable contract division. The literature on business renewal is more relevant, for it argues that in exceptional circumstances defunct firms or businesses can rejuvenate (BadenFuller and Stopford, 1994; Grinyer, Mayes and McKiernan, 1988; Pettigrew and Whipp, 1991). Until now, all the evidence has come from the so-called mature sectors, and the relevance to high technology sectors has yet to be established. For high technology firms, such as those in bioscience, there are serious technical issues to be confronted. Given the hyper-competitive nature of the environment (D'Aveni, 1994), the paradigmatic shifts in technology (Powell, Koput and Smith-Doerr, 1996) and the need for fast strategic moves (Brown and Eisenhardt, 1997), a serious question arises as to whether any renewal is possible and, if it is, whether the models of renewal in maturity are relevant.

The story of Celltech is unusual on two levels. First, it is an example of a mature high technology firm successfully engaging in renewal. Second, this renewal was focused around a strategy which enabled the firm to escape the gravity of exploitation and move towards a model of financially successful exploration. Its renewal is particularly unusual in that shareholder value (in terms of market capitalization) rose after renewal in spite of the fact that prior to the change in 1990 the firm had been only marginally profitable, and from 1990 to 1998 it has posted cumulative net losses of $£ 75.9$ million.

\section{Methods and data collection}

We sought to ensure the validity of our data through rigorous data collection. The first source of data was five interviews with senior executives inside our case company, and the analysis of extensive relevant company documents on investment, revenues, new product development, clinical trials, and alliances. The second was a search of public domain data on all independent drug biotechnology firms listed on the London Stock Exchange, which included Celltech. The third source of data was a series of interviews with executives from other bioscience companies, which helped to check our interpretation. In common with other case study research, a central output of the data collection and analysis process was the writing up of a detailed case study on Celltech (McNamara, Baden-Fuller and Howell 1997) ${ }^{3}$, with a companion note on the biotechnology sector (Eisenhardt, 1989). Triangulation of data sources helped to ensure validity (Jicks, 1979; Kirk and Miller, 1986). Respondent validation was employed, where executives from the organization commented on drafts of the case (Silverman, 1993; Whyte, 1984). Through a process of iterative rewrites, we sought to incorporate a shared understanding by both the researchers and the executives of the firm's story.

The executives in the company were keen to show us the competencies they had created and the dilemmas they faced. Being scientists they were highly articulate, meticulous about the data in support of their claims and able to point out sources of data which allowed us to explore the phenomena under discussion in this article. As such the interviews proved to be an excellent source of data and, despite the small number, showed a surprising degree of agreement and comprehensiveness. We have no indication that further interviews among seniors or juniors would reveal any significant new insights. To protect the reliability of our study a chain of evidence was created and maintained throughout the process (Yin, 1989). All interviews were transcribed (usually via tapes). Public documents such as annual reports, press comments and technical notes were searched in a methodical manner.

Understanding the processes of knowledge management and renewal in a high technology firm presents technical challenges to management researchers. Our team included a professor of chemical engineering who has experience of technical research in the field. His knowledge of the science was essential in understanding the nuances of the business and relating these to the managerial processes explored in this article.

Five managers were interviewed from differing levels in the organization. These were the Chief

\footnotetext{
3 The Celltech case study (with teaching note) is avail-
} able upon request from the authors. 
Executive of the group, the Director of Finance, the Chief Executive of the Therapeutics division, the Director of Research, and the Director of Development. Both the Directors of Development and Research were involved in a hands-on way with actual projects, having been Celltech project leaders in the 1980s and early 1990s. All except the Finance Director have PhDs in science and have previously worked for many years in the pharmaceutical sector. These five executives were pivotal in the reorientation of Celltech's strategy in the 1990s. We first interviewed the group Chief Executive following a broad interview schedule. This interview fleshed out the overall picture and a new set of interview questions was developed for the remaining four interviews. During early interviews issues arose which were unexpected, to which follow up questions were applied both within and across interviews. By the end of the five interviews, the interviewers felt that they had obtained an understanding of the firm. The last interview did not reveal any significant new information, rather it provided triangulation of existing data.

\section{An overview of Celltech}

Celltech can be viewed as having four basic historical periods, which link to the balance of the exploration and exploitation of knowledge. For the first decade of its existence, two separate strands of the business were grown: contract manufacturing and research (Biologics) and inhouse research and development (Therapeutics). The goal was to cover the costs of in-house R\&D with revenues generated by doing contract research on behalf of other firms. From Figure 1 we can see that after an initial period in which $R \& D$ expenditure exceeded Biologics turnover, by 1985 $\mathrm{R} \& \mathrm{D}$ amounted to less than $50 \%$ of turnover, and by 1987 this was at an all time low of $25.5 \%$, recovering to $50 \%$ by $1990 .{ }^{4}$ In 1987 there were marginally more employees located in the Therapeutics division than in Biologics. By 1990 the number of staff located in the Biologics contract research and manufacturing business was at an all

\footnotetext{
${ }^{4}$ Data on turnover and R\&D are only available from 1983 onwards. Data on the split of employees by division were not available prior to 1987.
}

time high of $60 \%$. Hence we refer to this as the Biologics period. During this period the firm developed strong technical capabilities (Dodgson, 1991), although executives commented that the firm was consequently very hierarchical and lacked capabilities in interdisciplinary research which were necessary for success in the development of innovative drugs.

In the second period (1990-1992), a new CEO joined the firm with a new perspective. He saw the future as being in the development of innovative new drugs in which Celltech had a slice of the action. As he puts it, 'the winners have to be the companies that are therapeutic because the value added is so huge'. The firm was formally split into two divisions, Biologics and Therapeutics, and the CEO implemented his new strategic vision by expanding the Therapeutics division. From Figure 1 we can see that this expansion resulted in an increase in the amount of inputs devoted to Therapeutics. The percentage of turnover devoted to own R\&D and the number of employees in the Therapeutics division both rose sharply. Within this division the firm developed a capability in the creation of innovative drugs from initial discovery through to regulatory clinical trials. This change in strategy required a shift away from core capabilities centred around technology application and towards interdisciplinary research to create new drugs as opposed to new technologies. Thus we refer to this period as re-asserting $R \& D$, where the role of $R \& D$ was accentuated, while the role of contract manufacturing and research, in terms of number of employees and turnover, was marginally reduced (see Figures 1 and 2).

In 1992 the third period began which lasted until 1996. From Figure 1 we can see that during this period the inputs devoted to Biologics and Therapeutics were largely in balance. The firm developed a strategy of collaboration with large pharmaceutical firms in the development of its drugs. We refer to this as the alliance period. The benefits of such collaboration were outlined by the firm as follows:

'They bring extensive expertise to the planning and conduct of clinical trials in order to seek registration for products in a timely manner. They have marketing expertise and strength in the therapeutic areas that should allow them to optimise the launch and market penetration of new products ... Collaborative agreements also demonstrate third party validation of the scientific 


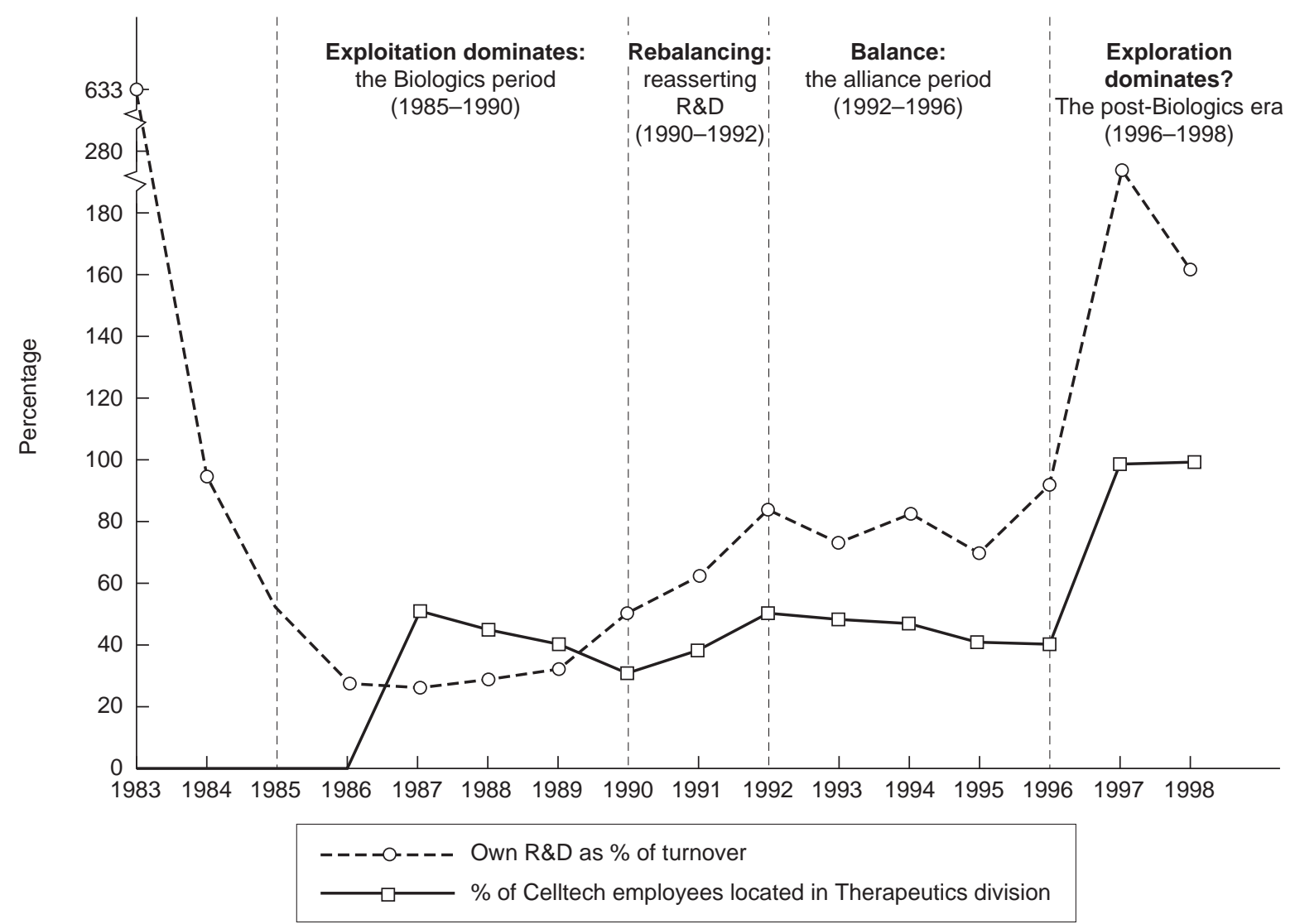

Figure 1. Input measures of exploration/exploitation balance: allocation of resources

and commercial potential of innovative discovery or development programmes.' (1996 Annual Report)

Current collaborators include some of the leading pharmaceutical firms in the USA and the EU. The quality of Celltech's collaborators and the number of drugs it has in both clinical trials and in discovery projects compares favourably with its major biotechnology rivals. This collaborative strategy enables Celltech to exploit its knowledge base before going to the end market, via cash milestone payments from collaborators, but without selling a full interest in the downstream property rights. Milestone payments and collaboration are not unusual in this sector. Celltech was, however, amongst the first in the UK to successfully implement this strategy. It is also unusual in the breadth and quality of its collaborators.

The fourth period began in 1996 when the Biologics division was sold for $£ 50$ million, thus we refer to this as the post-Biologics era. This signalled the final stage of Celltech's new direction. In 1990 Biologics dominated the firm to the detriment of R\&D. With the sale of Biologics Celltech had in six years converted itself into a firm solely focused on the R\&D of innovative drugs to the exclusion of contract manufacturing and research. From Figure 1 we can see that all inputs are now focused on own $\mathrm{R} \& \mathrm{D}$. The value of the firm has see-sawed over its life. From near bankruptcy in 1990, Celltech had been transformed. By 1998 it had a market capitalization of around $\$ 502$ million. An analysis of stock market performance shows that Celltech ranked eighth out of 50 independent European biotechnology firms, having experienced a $25 \%$ increase in share price in 1998 (McNamara, 1999). This renewal occurred not by intensifying the firm's focus on the exploitation of organizational knowledge, but rather by refocusing on exploration. 


\section{Exploration/exploitation as a lens in understanding Celltech's renewal}

This transformation from Biologics to Therapeutics can be explained in terms of the exploration/ exploitation balance. We can view investment in Biologics as essentially being an investment in exploitation. Celltech had developed world-class technical capabilities that leveraged the firm's knowledge of antibodies and recombinant DNA through contracted manufacturing. It is a classic example of Levinthal and March's (1993) definition of exploitation as 'the use and development of things already known'. Incremental development of these capabilities did occur, but only in the context of learning by doing in the contract research division. Investment in contract manufacturing had a rapid feedback from the market in terms of contracted revenues.

Celltech's investment in Therapeutics can be viewed as knowledge exploration in Levinthal and March's (1993) terms where exploration is 'the pursuit of new knowledge of things that might come to be known'. Drug discovery requires that knowledge from multiple technical disciplines (for instance, molecular biology and medicinal chemistry) be combined in the creation of an innovative compound that can enter clinical trials. In 1990 this exploration became more intense as the firm sought to develop its capabilities in interdisciplinary drug discovery. The feedback from the market is not as clear, nor as fast, as in the case of Biologics' contracts. The discovery of a compound takes on average 3.3 years, though in many cases considerably longer; the drug development process is estimated to take a further 8.2 years on average (Parexel International, 1996). Only 5 in 5000 compounds that enter discovery programmes are estimated to make it to developmental clinical trials, and only one of these to make it on to the market (Berry, 1996). The cost of taking a drug through this process is estimated to be in the region of $\$ 300-\$ 500$ million (BIO, 1996).

From Figure 2 we can see that Celltech was experiencing very considerable growth in Biologics turnover from 1987 to 1989. Gross margins attributed to the Biologics activity, while falling, were quite high, ranging from over $31 \%$ to $12.5 \%$. On the back of Biologics' success the firm was able to invest $£ 17.3$ million in Therapeutics R\&D during this period, while also generating a net profit of $£ 900000$. Therapeutics was not generating any turnover during this period. In this context one

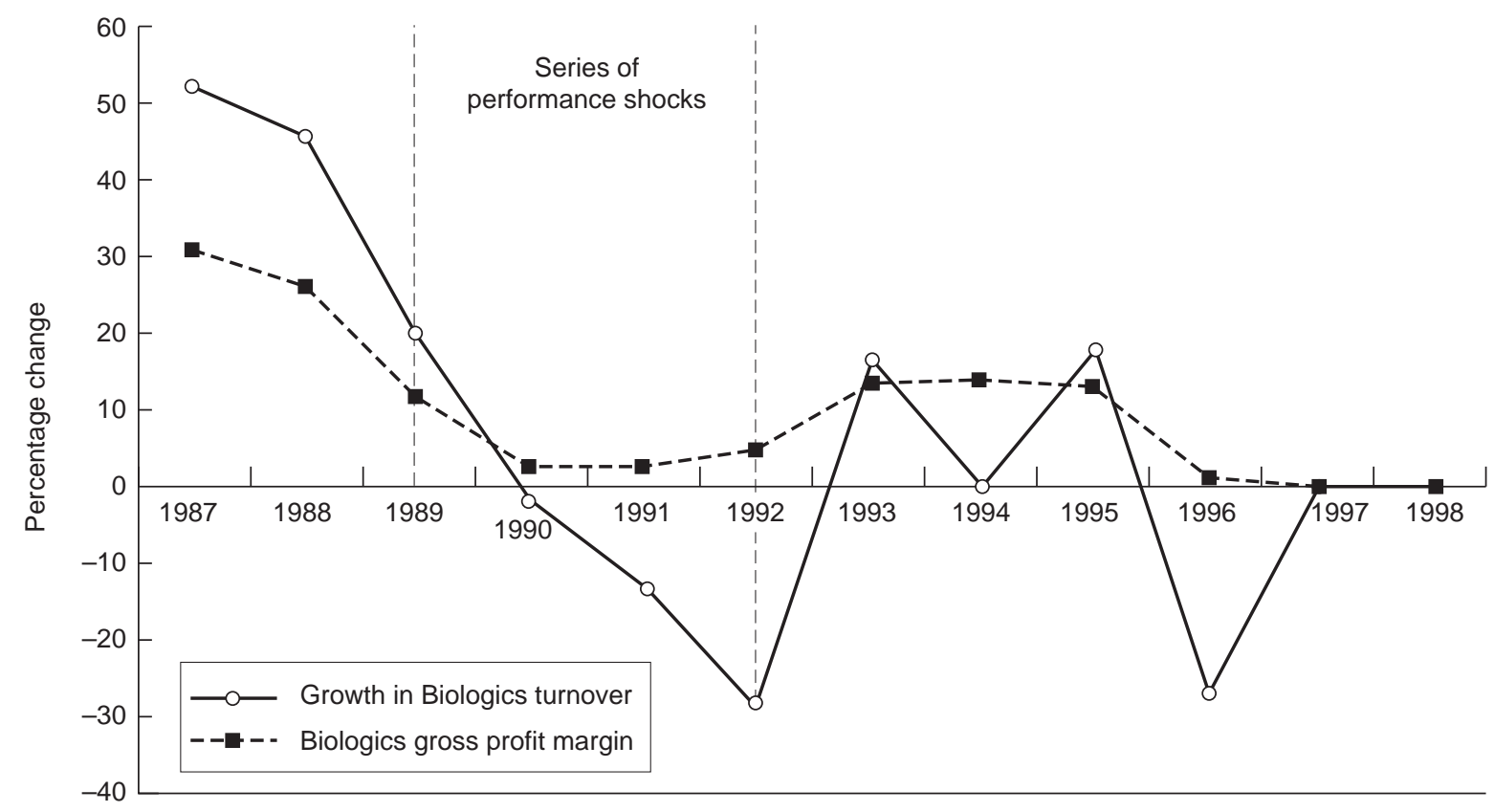

Figure 2. Performance of Celltech Biologics 
can see that for a firm such as Celltech in the 1980s, the temptation to focus resources on exploitation rather than exploration was very real.

The balance between exploration and exploitation in Celltech can be seen from two perspectives: allocation of resources to each activity (Figure 1) and revenues generated (Figure 3). As noted earlier, from Figure 1 we can see that from 1985 to 1990 investment in Celltech's own R\&D as a percentage of group turnover initially declined, and remained below 32\% until 1990, when it dramatically increased to $49 \%$ with the arrival of the new management team. The number of employees working in the Therapeutics division declined over the period from 1987 to 1990. Employee numbers is a key metric as both R\&D and contract manufacturing and research are knowledge and labour intensive activities.

In addition to a rising commitment to Biologics in terms of inputs, as seen in Figure 1, there was a parallel rise in level of turnover, or outputs, that Biologics generated (see Figure 3). Combining Figures 1 and 3 we can see that during the period from 1985 to 1990 exploitation (Biologics) came to dominate over exploration (Therapeutics).
The reasserting R\&D period from 1990 to 1992 can be seen in Figure 1 in terms of a sustained rise in the percentage of employees located in Therapeutics. New employees were hired within Therapeutics while there were redundancies within Biologics. Figure 3 indicates that in terms of one simple output measure, turnover, the Therapeutics division was also beginning to make an impact. Retrenchment in the Biologics division can be seen in Figure 3 in terms of a decline in turnover generated by the division. Thus we can see that the imbalance between Biologics and Therapeutics in terms of resource inputs and revenue outputs began to be reversed.

The alliance period represents a time of sustained balance between the inputs allocated to both exploration (Therapeutics) and exploitation (Biologics). From Figure 1 we can see that the number of employees located in each division is largely in balance. From Figure 2 we can see that the performance in Biologics in terms of margins improved over the period. From Figure 3 we can see that both divisions experienced a rise in revenues up to 1995 , and a proportional decline in 1996. Thus over a period of half a decade, from

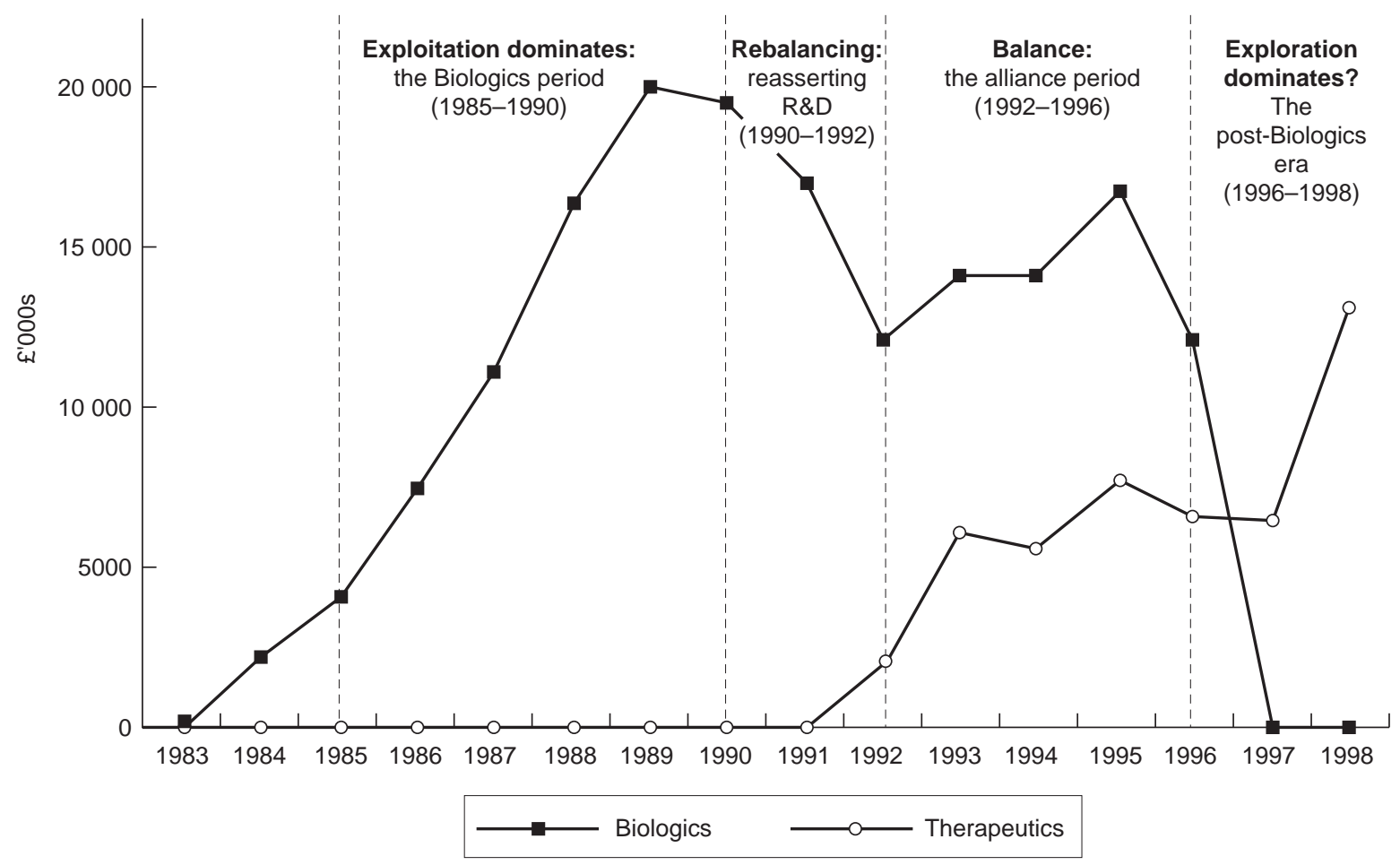

Figure 3. Output measure of exploration/exploitation balance: revenue 


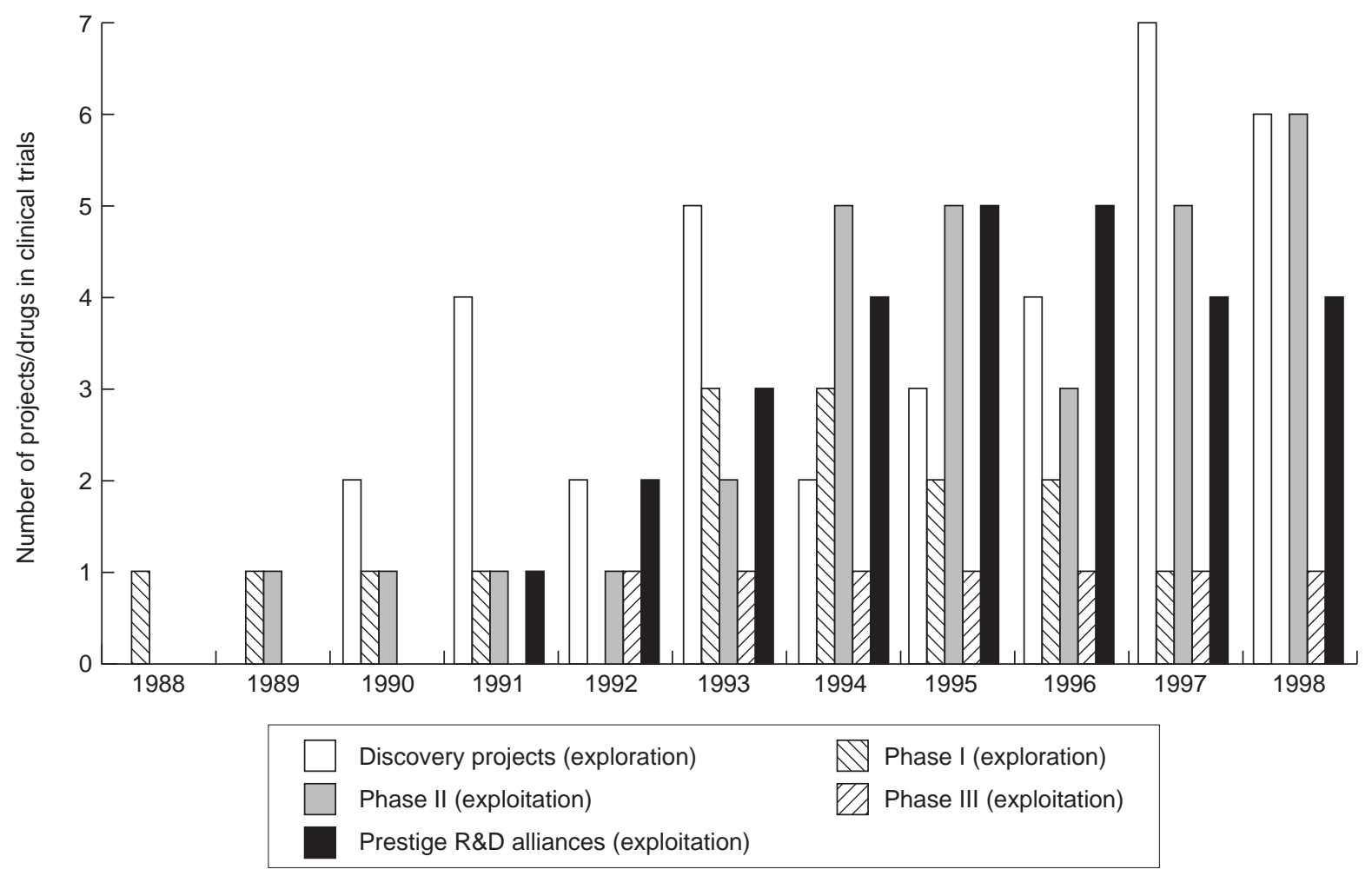

Figure 4. Balancing exploration and exploitation in Therapeutics

1992 to 1996, exploration and exploitation in terms of inputs (Figure 1) and outputs (Figures 2 and 3 ) were largely in balance.

\section{Exploration/exploitation inside Therapeutics}

At the start of the fourth period, in 1996, the Biologics division was sold off. Therapeutics had developed its own sophisticated balance of exploration and exploitation dimensions. There were (and still are) three aspects of exploration within Therapeutics: discovery of new drugs; phase one clinical trials; and development of a capability in collaboration with large firms. Exploration within this division can be seen in its purest form as the discovery of new drugs. Drug discovery by its very nature involves 'the pursuit of new knowledge of things that might come to be known' (Levinthal and March, 1993). The objective is the discovery of a new innovative compound which tackles an illness that currently lacks a drug therapy, or a compound that is based on a sufficiently novel combination of knowledge that it does not violate current patented compounds. From Figure $4^{5}$ we can see that from 1990 to 1998 Celltech has considerably increased the number of identified discovery projects.

The second exploration activity in Therapeutics is the movement of a compound from discovery into Phase I clinical trials. Phase I trials seek to establish the safety of the drug on healthy volunteers. These trials represent about $10 \%$ of the cost of performing clinical trials (Parexel International, 1996). Phase I trials represent the first application of the drug on humans. While testing on animals may have occurred in pre-clinical trials, the move to man is uncertain. Much new knowledge is generated at this stage. From Figure 4 we can see that this form of exploration peaked during the period of balance between 1992 and 1996, and that a reduction in Phase I trials during 1997 and 1998 has been offset, in exploratory

\footnotetext{
${ }^{5}$ Data on the number of drugs in clinical trials were not available prior to 1987 .
} 
terms, by a rise in the number of identified discovery projects.

The third exploration activity is the creation of the capability to collaborate with large pharmaceutical firms. By 1990 two drugs were in clinical trials, and the number has risen dramatically since then (see Figure 4). This has been achieved by accessing the drug development capabilities of large pharmaceutical partners through collaboration, with the partner taking the lead in the management of clinical trials. Through interaction with pharmaceutical partners on development projects, Celltech has, according to executives within the firm, developed a capability in managing collaborations with large firms. The initial development of this capability can be viewed as another example of exploration.

Exploitation is defined as 'the use and development of things already known' by Levinthal and March (1993). We can observe two major forms of development and use (exploitation) inside Therapeutics. First is the conduct of Phase II and Phase III clinical trials, which can be viewed as the development of things already known. These trials are essentially development and use of knowledge, as embedded in the compound, rather than classic exploration. Phase II trials involve establishing the tolerable range and most effective dosage on patients suffering the illness. Phase III trials involve further controlled tests where the efficacy and safety of the drug is compared relative to other treatments. Phase II trials represent about $30 \%$ and Phase III trials about $60 \%$ of the costs of the clinical trial process (Parexel International, 1996). From Figure 4 we can see that the number of Phases II and III clinical trials increased marginally in the period of reasserting $R \& D$ (1990-1992), while in the alliance period (1992-1996) there was both an increase (in 1993) and a slight decline (in 1996). In the post-Biologics era there has been an increase in the number of drugs in Phase II trials, representing an increasing focus on exploitation.

The second form of exploitation is the management of prestige alliances. Prestige alliances can be viewed as predominately exploitative. This exploitation occurs on four fronts. First, alliance partners provide milestone payments to Celltech for achieving prescribed stages in the discovery and development of a drug. Second, prestige alliances enable Celltech to access world-class drug development and marketing capabilities, which enhances the value of their drug portfolio. This access is critical to the development of the knowledge embedded in the discovered compound. Celltech had little development experience in 1990, and no experience of the worldwide marketing and distribution of drugs. Access to these capabilities enables it to exploit its discovered compounds. Third, through these collaborations Celltech has over time learned to develop, or deepen, its own initially limited drug development capabilities, such that it now seeks to take on an increasing role in the management of clinical trials, particularly Phase I and Phase II trials. Such learning can be viewed as development of current knowledge under the Levinthal and March (1993) definition of exploitation. Fourth, alliances with prestige partners bring with them a validation of both Celltech's technology and its corporate strategy. This validation was vital to Celltech in raising its perceived value among investors prior to its launch on the London Stock Exchange in 1993. Post-1997 it was also vital in the recovery of Celltech's share price after the collapse of a Phase III clinical trial and the loss of Bayer as a prestige alliance partner (McNamara, 1998).

Figure 4 offers a set of metrics from which we can see the balance between exploration and exploitation that has been achieved within the Therapeutics division. From Figure 4 we can see that the amount of exploration within Therapeutics has risen over time. In 1990 there were two discovery projects and one Phase I clinical trial. By 1998 there were six discovery projects but no Phase I clinical trials; the renewal of Celltech coincided with a rise in the number of exploration projects inside Therapeutics. From Figure 4 we can see that prior to 1993 the number of exploration projects within Therapeutics exceeded the exploitation activities, however from 1993 onwards the number of exploitation activities increase. By 1998 there is a greater emphasis on exploitation projects than exploration, suggesting that Celltech may once again be moving out of balance.

\section{From core rigidities to new core competencies: exploiting shocks to overcome organizational inertia}

How did Celltech engineer the changes? In particular how did it reverse the decline of exploration 
and create the more balanced, higher value Therapeutics division? Our interview data revealed the following to be important:

- the existence of a series of crises in 1990 (as partially reflected in Figure 2);

- a new CEO and top management;

- redundancies in the Biologics division simultaneous with the hiring of thirty medicinal chemists, injecting a new knowledge base into Therapeutics;

- the reforming of teams from a functional organization of technically orientated teams to multi-functional project-orientated teams; and

- the development of a shared culture and language across the firm.

In the next few pages we elaborate on what these changes entailed and why they were important.

It was clear that at the end of the 1980s there was a high level of inertia and resistance to change from within Celltech. Biologics had been the source of Celltech's revenue growth. The old management had committed itself to a technology focus, not interdisciplinary research. Strong collaborative ties had been formed with academia and were viewed as central to the future of the firm (Dodgson, 1993). At its foundation, the central focus of Celltech had been a technology transfer agreement with the Medical Research Council which sought to exploit academic knowledge commercially. From contemporary annual reports and Dodgson's (1993) study of Celltech's first decade, we can see that management was strongly committed to the continuation and strengthening of this agreement, having negotiated in 1988 an extension of the contract until 1993. Employees had come to jokingly refer to Celltech as the 'University of Slough'. One executive noted that:

'Almost a third of its R\&D spend was on these [academic] collaborations. I can say that almost universally they were very non-productive. They were quite a cash drain on the company.'

On the Therapeutics side, research seemed to lack focus and was largely unproductive (some departments consisted of only two people). Change would have to overcome the firm's past commitment to collaboration with academia, and the accompanying culture, and a reliance on profits from Biologics based upon the development and application of technological capabilities reinforced by academic ties and hierarchical structures.

\section{Creating a crisis}

Huff, Huff and Thomas (1992) note that shocks are needed to engineer change and that that rarely is a single shock to a managerial system sufficient. A single shock can be rationalized away as an aberration, or a temporary occurrence. Ordinarily, as in the case of Celltech, a radical departure from the status quo is only triggered by a series of significant shocks to the system, which are bunched closely together. Celltech encountered a series of three distinct shocks. First came the financial shocks of 1989 to 1992. We can see from Figure 2 that Biologics's gross margins were in considerable decline from 1988 to 1990 . The rate of growth of Biologics's turnover was declining over this period, and from 1990 to 1992 was negative. Declining performance over a period of several years could not easily be explained away. Second, Celltech's major shareholder, with a $36.4 \%$ stake, went bankrupt in 1990. This placed further pressure on Celltech to address its poor financial performance. Third, the retirement of both the founding CEO and Research Director was scheduled for 1990. This, combined with the two other shocks, offered a window of opportunity in which change could be initiated and inertial forces overcome.

The challenge that these shocks posed should not be underestimated. Shareholder pressure for change was intense. One senior executive recalled the mood of the time, saying:

'It was relayed to us by the original investors that
"You are smart guys. You can tell us a nice story,
but how do we know it's valid?" You see, six or
seven years ago, very few financial institutions
knew anything much about science, let alone the
pharmaceutical industry. They felt that they had
already been hoodwinked by one group of man-
agement and so what they said was we had to do
something quite distinctive that made them
believe there was something special about us.'

To impress the shareholders new directions in strategy were necessary, new capabilities had to be developed and scarce resources refocused. A new management team was hired which had to drive Celltech towards its ultimate goal of becoming a 
large R\&D-led company that took drugs to market. The old capability focused on the contract manufacturing of antibodies and collaborative links with universities to maintain a leading edge functional technology focus (Dodgson, 1991, 1993). New capabilities needed to be developed to focus on new product development, rather than technical excellence. As one executive commented:

'An organisation of this type is not judged by the output of scientific papers. It is actually judged by its ability to come up with technologies which in turn will lead to therapeutic entities. The technology itself is fairly valueless until you convert it into something practical ... What I think we emphasised, if anything, was to say that, if that is the basis on which we are judged, then clearly if we cannot convert our technology into practical realities, we will be complete failures.'

\section{Unlearning, reorganizing and new recruits}

As capability development is path dependent, behaviour can become deeply embedded and inhibit, rather than promote, actions that add value. Unlearning is defined by Hedberg (1981) as 'a process through which learners discard knowledge' which is 'obsolete and misleading'. Imai, Nonaka and Takeuchi (1985) have equated this process of unlearning with Schumpeter's process of creative destruction. Unlearning is critical to the broader issue of organizational learning processes, as has been noted by Bettis and Prahalad (1995) and Huber (1991). New orgnizations are less disadvantaged than are established firms because they have less to discard.

The task of 'unlearning' can be viewed as a considerable organizational challenge, because the effort and risks involved in switching from one capability to another can be substantial. The interplay between the bundles of resources and capabilities necessary to create a new capability will, at the outset, be poorly understood since the creation of organizational knowledge is by definition a complex and uncertain process. Kogut and Zander (1992) articulate this risk in their study when they note that:

'Switching to new capabilities is difficult as neither the knowledge embedded in the current relationships and principles is well understood, nor the social fabric required to support the new learning known.'
In the case of Celltech the switch from technological capability to a more therapeutic-based capability was a considerable challenge. Renewal was not just a matter of changing strategic direction. More fundamentally, it required a change in the way staff thought about science and how research was organized. This ideological change is encapsulated in the move away from an almost academic culture, where close collaborative ties with academia were mirrored in structures that executives described as like an academic institution. As one executive commented, change required a shift away from an academic philosophy of technical excellence, measured in part by the number of scientific papers published, and towards a more commercially-minded focus on getting products into the clinic. Another executive noted that this required 'almost a sea change in the way that we were organised'.

Research was reorganized with teams focusing around three therapeutic targets selected by the new management. Biologists of differing specialities were put in teams to work towards a common goal. Previously they had worked within functional groupings. Now scientists of differing functional expertise worked together within specific projects. Each project had a goal of bringing a drug to clinical trials, thus improving the firm's research productivity. This meant that teams no longer focused on the development of technical expertise alone, but upon the combination of technical expertise to develop novel therapeutic compounds.

Mixing old and new functions within common projects required scientists to learn about issues outside their previous speciality. To do this they had to focus more on these skills and less on their specialist skills, which had been their sole previous focus, thus facilitating unlearning. This process of socialization, a new challenge, a new vision of the future, and a narrowly defined focus of work (three therapeutic areas with individual teams looking at narrower issues) enabled a shift in capability to occur. (The success of this strategy, in terms of research productivity and acceptance by stakeholders, cumulated in the divestment of Biologics.)

Intellectual diversity is essential for change and exploration to create new capabilities (Carley, 1992; Javanovic and Nyarko, 1995; Simon, 1991). It was the new senior management recruited from outside Celltech which brought with it this new 
perspective on how the firm could achieve success. Additionally, the senior management team brought new skills, including knowledge of asthma therapies, which had not previously been a focus at Celltech. The strategy also involved hiring 35 medicinal chemists who were dispersed across the projects as required. These new staff members enlarged Celltech's skill base from biotechnology and into the more traditional medicinal chemistry skills of pharmaceutical firms. But all this change was risky. Old employees might not have adapted to the new change. New teams might not have 'gelled'.

\section{Systems to foster the coexistence of exploration and exploitation}

What other factors did Celltech use to engineer the change? Many have noted that a firm's social system plays an important role in determining the speed and path of learning (Brown and Duguid, 1989; Imai, Nonaka and Takeuchi, 1985; Kay, 1993; Orr, 1990; Simon, 1991). Changes in either the degree of control maintained over social interaction between actors within the firm or the structure of communications between actors can facilitate improvements in shared understanding between organizational members of how tasks should be performed (Blacker, 1995; Cyert and March, 1963; Huber, 1991; Nonaka and Takeuchi, 1995).

Nonaka's work indicates the central role of social processes in the 'spiral' of knowledge creation, which he views as a key to the success of firms (Nonaka 1994; Nonaka and Takeuchi 1995). In Nonaka's view the development of capabilities within firms involves a process of the conversion of tacit knowledge into explicit knowledge, explicit into tacit, and from one form of explicit or tacit knowledge to another. For Nonaka the driving forces for these transfers between forms of knowledge are attempts to create new knowledge and to improve the efficiency of integration of existing knowledge into the firm. Nonaka sees movements to or from tacit knowledge as involving a high degree of social interaction.

The new management of Celltech paid particular attention to managing exploration for new knowledge and exploitation of the knowledge derived from exploration activities by creating a series of systems to manage drug discovery and development. The management of current projects and the search for new research ideas involves both formal and informal systems. Close proximity is an informal mechanism; all staff are located on one site and the layout of the building is specially designed to facilitate interactions. More formal mechanisms include quarterly reviews of the progress of projects. If they are not meeting objective milestones, then reasons are elicited from the team. If senior management believes that these problems are not solvable within the present budget and time frames due to resource or capability deficiencies, then projects are quickly shut down. Annual reviews enable the scientists to interact with senior management in budget allocations for the coming year. Strategic research reviews are conducted periodically. Through these reviews, ideas on new projects bubble up. Often the original ideas upon which new project proposals submitted during the research review are based stem from the conferences which the scientific staff have attended, or literature they have read, in which interesting ideas were raised and then independently pursued by themselves during slack time. A senior executive describes the essence of how new ideas bubble up, culminating in the strategic review, as follows:

\footnotetext{
'You don't say that we are going to have a meeting next Thursday. There usually is a lot of discussion about the ideas. Eventually they [the proposals] come forward, but they don't come forward as a surprise on Thursday afternoon, to be decided by the end of the day. Because we are a small company you are always talking to people, so you have a good idea of what ideas are being discussed. It is almost a constant process of seeing what's new, what we might do, what's exciting.'
}

\section{Common codes and shared language}

For new knowledge to be created and current knowledge to be integrated across the organization, there needs to be investment in a shared language amongst the individuals involved (Blacker, 1995; Cohen and Levinthal, 1990; DeGeus, 1996; Nonaka and Takeuchi, 1995). Just as academics develop precise codes to facilitate the transfer of ideas amongst themselves, so people in organizations generally need to express their ideas in terms that their colleagues understand. Given the central role of individuals in knowledge creation, without the transfer of knowledge between individuals organizational knowledge would 
be unlikely to develop to a commercial level, if at all. The creation and development of a basic common language is a costly and uncertain task. When creating and integrating complex knowledge into organizational routines and directions, it is likely that the opportunity for misunderstandings will develop. This integration of knowledge occurs across several functions, and the problem of shared knowledge becomes more pronounced.

In the case of Celltech, when it changed from a discipline and technology-based capability to a therapeutic capability, chemists were thrust together with biologists leading to differences in common understandings. Disciplines that within Celltech had previously worked in hierarchical isolation now had to converse and work side by side on an operational level to integrate their diverse knowledge into the production of a single drug. This required colleagues to train each other in the basics of their discipline. In so doing, knowledge overlaps and redundancies were created. An understanding of the language and mindsets of other disciplines facilitated a deeper understanding of the problems facing the firm. Triggers for innovative solutions were set off through this process of developing shared understanding at the level of bench scientists. The Director of Research summed up the effect of putting people with different skill bases into common teams by noting:

\begin{abstract}
'We were very much organised along technical disciplines for quite a long time, which gave us a very good strength in technology but maybe not a good strength in biology. We found that when we moved into the therapeutic areas we were able to get people to be focused on biological questions so that they built up their biology base. So we had people who had a lot of interest in inflammation, and these people built up a knowledge base around inflammation as opposed to being molecular biologists, or cell biologists or biochemists.' The reorganisation 'challenged [researchers] with learning more about the biology, rather than just learning about techniques and technology'.
\end{abstract}

The need to create shared language at the operational levels of the firm was mirrored by the need to create a shared understanding with external collaborators. The search for and management of external collaborations was conducted at the middle and higher levels of management. Senior management at Celltech found that its collaborators tended to think differently. This makes communications across firm boundaries a slow process, where firms learn to talk to each other, and learn the meaning of their objectives, mindsets and systems, thus slowing the transfer of knowledge needed to collaborate.

An example was Celltech's collaboration with Bayer. The decision-making structures of the firms were quite different. Bayer focused on indepth commercial analysis of the project first, and then on meticulous large-scale clinical trials. According to a Celltech executive, decisions taken by the Bayer members of the project team sometimes needed to be ratified by several layers of management. Celltech did not focus on commercial analysis in as much depth as Bayer, nor did it have a lot of experience as a company in conducting large-scale clinical trials, especially at Phase III. Celltech's expertise was in the discovery of novel compounds, and there was only one level of management between the project manager and the CEO. These issues, amongst others, led to different ways of working in Celltech and Bayer. To work together these alternative systems had to be understood by the Celltech management and accommodated for. This initially slowed the project, however it offered excellent opportunities to learn the management of alliances with large firms. This process can also help a firm to recognize and learn of gaps in its own knowledge bases, stimulating the managerial processes of both exploration and exploitation. For example, Celltech recently hired a senior manager with expertise in the marketing of pharmaceutical products to fill a gap in its knowledge of commercial analysis. Its expertise in clinical trial development has been deepened through learning from alliances with Bayer and other large pharmaceutical firms, all of which are widely experienced in the management of largescale clinical trials.

\section{Discussion}

The renewal of Celltech provides four key lessons. First, contrary to suggestions in the literature, renewal is possible through a movement away from exploitation and towards exploration. The key to such a renewal strategy is that it be based firmly on the principle of adding shareholder value. By moving away from the low margin but profitable Biologics, and towards loss-making 
drug discovery and development, the firm increased its market value. During this period the firm raised a further $£ 41.7$ million from shareholders. The new management realized that shareholders were not interested in short-term profits but rather in longer-term capital gains. Paradoxically, bigger losses that focus on the right sort investments can mean bigger potential gains. By intensifying investments in exploration to develop a strong Therapeutics division, the capital value of Celltech rose, despite an intensification of losses to $£ 75.9$ million due to increased R\&D.

Celltech moved to exploration not just in terms of new scientific capabilities, but also in terms of new managerial capabilities. This is a key lesson of the Celltech renewal. Renewal based on exploration requires coordinating changes in both technical and managerial capabilities. Celltech would have failed if it had only renewed its technical capabilities and ignored the creation of capabilities in managing collaboration and a new relationship with shareholders.

The second lesson is that the management of crisis and galvanizing the commitment of key organizational actors is essential in overcoming organizational inertia to renew. This is not a new lesson, having been championed by Baden-Fuller and Stopford (1994), Pascale (1990) and others. In Celltech, new management entered the firm but was cautious at first, galvanizing the commitment of a key group of scientists and administrators prior to announcing the change in strategy from technology focus to project groups orientated around the creation of individual drugs. Having gained the commitment of the key scientists in the firm the sense of crisis, which had been growing amongst staff, was relieved. The new team also brought with it a sense of credibility, being made up of accomplished research scientists and pharmaceutical administrators from Roche Holdings, amongst others. The key here is that a relatively small number of new managers stepped into the crisis, untainted by its past, galvanized a small number of key actors within the organization, and then presented the staff with a new strategic vision which was not only endorsed as acceptable by shareholders, but which also excited and motivated staff. As one manager put it, the staff were released from the constraints of contract manufacturing and research, in which they had no long-term stake, and could now engage in big, liberated science where their scientific skills and creativity could be profitability pursued.

The third lesson is that for a firm to renew based on exploration it needs to stimulate knowledge creation through an injection of both external and internal diversity. External diversity was infused through the arrival of the new senior management team. This brought new ideas on what the strategic focus of the firm should be, in addition to a knowledge of how large pharmaceutical firms operate, which was fostered to develop a capability in managing prestige alliances. External diversity also came in the form of the new medicinal chemists. Inappropriate knowledge was partially extinguished by the redundancy of 60 staff, which when combined with structural changes signalled that the old ways of doing things were not to continue. Internal diversity was stimulated by the creation of the new teams organised around drug projects. Executives noted that the majority of new project ideas came from the creative resources of those staff who existed in Celltech prior to 1990.

The fourth, and we believe most important, lesson from the renewal of Celltech is that for exploration to be sustained it is vital that systems be installed to ensure that the outputs of exploration activities are clearly linked to the firm's exploitative efforts. These processes occurred at two levels of the organisations. At the operational level, new capabilities in interdisciplinary research were developed. At the upper management level, capabilities in the management of collaboration were developed. Regular research reviews were initiated which enabled a project to be assessed in terms of its ability to deliver tangible results in a timely and cost effective manner, and the ability of the project to attract and retain collaborators (the relationships with which were identified, cultivated and managed by senior management). As drugs exited discovery projects, they were assessed by a Product Development Panel, which sought to assess if each drug should move into the development, or exploitation, stage of the $\mathrm{R} \& \mathrm{D}$ process. These systems ensure that a tight linkage between exploration and exploitation is maintained.

Systems were also put in place to ensure that a balance between exploration and exploitation was maintained over time. As drugs exit the discovery stage, the research review process seeks to identify new discovery projects. Ideas bubble 
up from the operational level and are assessed by the middle management, and reviewed by senior management. This process, coupled with a system of strategic review, seeks to ensure that exploitation does not drive out exploration in Celltech. This temptation is real because as a drug moves through Phase II and three trials the costs rise dramatically, while the time to market is diminishing. The temptation is to cut investment in discovery projects so that these funds can be devoted to late stage clinical trials.

\section{Conclusions}

Theoretical development has posed a challenge to organizations. On the one hand they are told that they must balance exploration activities with exploitation activities if they are to maximize their value. On the other hand, firms are told that in general, maturity brings inertia and decline as exploitation drives out the creation of new ideas. All too often, people have drawn the conclusion that high technology firms live on a knife edge and that having fallen, renewal is likely to be almost impossible (Christensen, 1997) or the result of serendipity (Burgelman, 1994).

Our case study throws into doubt some of these theoretical presumptions. We document the renewal of a high technology firm from near bankruptcy and paralysis to a high level of success. More importantly, we demonstrate that this renewal was not 'accidental', but rather the application of well tried and tested managerial techniques which included a new CEO, the hiring of new staff from a different discipline, the formation of new team structures and the infusion of new organizational processes.

Much of the past research into the balance between exploration and exploitation has relied on the generation of mathematical models as opposed to organizational case studies (Cohen and Levinthal, 1990, 1994; Levinthal, 1997; March, 1991). Instrumental cases can be useful in theory testing (Eisenhardt, 1989) and theory extension (Yin, 1989) or theory development (Sutton and Straw, 1995). We carefully selected the Celltech case such that it could act as an instrumental case allowing us to explore whether or not it was possible both to renew based on turning back the tide of exploitation and to maintain a balance between investments in exploration and exploitation. The literature would suggest that both phenomena are difficult, and by implication rarely achieved. By employing an alternative method to prior research, based on a longitudinal case study as opposed to a mathematical model, this article has offered further insights into both the process of renewal and the management of the tension between exploration and exploitation inside a high technology firm.

Based on our single case study we do not suggest that all failing high technology firms can renew, but we would suggest that future case researchers examine the relevance of well tried and tested renewal techniques to those which do succeed (and a sample of those which do not). We also suggest that research be undertaken into firms which have sustained a balance of exploration and exploitation over time to assess whether their achievements are quirks, and therefore do not challenge the theoretical proposition that there is a natural tendency for exploitation to drive out exploration, or the result of applying definable management techniques. Further multiple case research could reveal whether the Celltech case is unique (Yin, 1989) or one of many cases which cast doubt on prior theoretical generalizations.

\section{References}

Baden-Fuller, C. and J. Stopford (1994). Rejuvenating The Mature Business. Harvard Business School Press, Boston, MA.

Berry, J. (1996). 'The Drug Development and Approval Process', PhRMA Drugs in Development. http:www.phrma.org/ charts/approval.html.

Bettis, R. and C. Prahalad (1995). 'The Dominant Logic: Retrospective and Extension', Strategic Management Journal, 16(1), pp. 5-14.

BIO (Biotechnology Industry Organisation) (1996). Editors and Reporters' Guide to Biotechnology. BIO, http/www.bio/ erguide.html.

Blacker, F. (1995). 'Knowledge, Knowledge Work and Organisations: An Overview and Interpretation', Organisation Studies, 16(6), pp. 1021-1046.

Brown, J. and P. Duguid (1989). 'Innovation at the Workplace, a Perspective on Organisational Learning', CMU Conference on Organisational Learning, May.

Brown, S. and K. Eisenhardt (1997). 'The Art of Continuous Change: Linking Complexity Theory and Time-paced Evolution in Relentlessly Shifting Organisations', Administrative Science Quarterly, 42(1), pp. 1-34. 
Burgelman, R. (1994). 'Fading Memories: A Process Theory of Strategic Business Exit in Dynamic Environments', Administrative Sciences Quarterly, 39(1), pp. 24-56.

Burgelman, R. and A. Grove (1996). 'Strategic Dissonance', California Management Review, 38(2), pp. 8-28.

Carley, K. (1992). 'Organisational Learning and Personnel Turnover', Organisational Science, 3(1), pp. 20-46.

Christensen, C. (1997). The Innovator's Dilemma: When New Technologies Cause Great Firms to Fail. Harvard Business School Press, Boston, MA.

Cohen, W. and D. Levinthal (1989). 'Innovation and Learning: The Two Faces of R\&D', The Economic Journal, 99(397), pp. 569-596.

Cohen, W. and D. Levinthal (1990). 'Absorptive Capacity: A New Perspective on Learning and Innovations', Administrative Science Quarterly, 35(1), pp. 128-152.

Cohen, W. and D. Levinthal (1994). 'Fortune Favours the Prepared Firm', Management Science, 40(2), pp. 227-251.

Collis, D. (1991). 'A Resource Based Analysis of Global Competition: The Analysis of the Global Bearings Industry', Strategic Management Journal, 12(Summer), pp. $49-68$.

Cyert, R. and J. March (1963). A Behavioural Theory of the Firm. Prentice-Hall, Englewood Cliffs, NJ.

D'Aveni, R. (1994). Hypercompetition: Managing the Dynamics of Strategic Manoeuvring. Free Press, New York.

DeGeus, A. (1996). 'Planning as Learning'. In: K. Starkey (ed.), How Organisations Learn, pp. 92-99. International Thomson Business Press, London.

Dodgson, M. (1991). 'Technology Learning, Technology Strategy and Competitive Pressures', British Journal of Management, 2, pp. 133-149.

Dodgson, M. (1993). 'Learning, Trust and Technological Collaboration', Human Relations, 46(1), pp. 77-95.

Eisenhardt, K. (1989). 'Building Theories from Case Study Research', Academy of Management Review, 14(4), pp. 532-550.

Grinyer, P., D. Mayes and P. McKiernan (1988). Sharpbenders: The Secrets of Unleashing Corporate Progress. Basil Blackwell, London.

Hedberg, B. (1981). 'How Organisations Learn and Unlearn'. In: P. Nystrom and W. Starbuck (eds), Handbook of Organisational Design, pp. 3-27. Oxford University Press, New York.

Hendry, C. (1996). 'Understanding and Creating Whole Organisational Change Through Learning Theory', Human Relations, 49(5), pp. 621-641.

Herriott, S., D. Levinthal and J. March (1985). 'Learning from Experience in Organisations', American Economic Review, 75(2), pp. 298-302.

Hoskisson, R. and M. Hitt (1994). Downscoping. Oxford University Press, New York.

Huber, G. (1991). 'Organisational Learning: The Contributing Processes and the Literatures', Organisational Science, 2(1), pp. 88-115.

Huff, J., A. Huff and H. Thomas (1992). 'Strategic Renewal and the Interaction of Cumulative Stress and Inertia', Strategic Management Journal, 13, Summer Special Issue, pp. $55-75$.

Imai, K., I. Nonaka and H. Takeuchi (1985). 'Managing the New Product Development Process: How Japanese
Companies Learn and Unlearn'. In: K. Clark, R. Hayes and C. Lorenz (eds), The Uneasy Alliance, MA, pp. 337-381. Harvard Business Press, Boston.

Javanovic, B. and Y. Nyarko (1995). 'The Transfer of Human Capital', Journal of Economic Dynamics and Control, 19(5-7), pp. 1033-1064.

Jicks, T. (1979). 'Mixing Qualitative and Quantitative Methods of Triangulation in Action', Administrative Science Quarterly, 24, pp. 602-611.

Kay, J. (1993). Foundations of Corporate Success. Oxford University Press, Oxford.

Kirk, J. and M. Miller (1986). Reliability and Validity in Qualitative Research. Sage, Newbury Park, CA.

Kogut, B. and U. Zander (1992). 'Knowledge of the Firm: Combinative Capabilities and the Republication of Technology', Organisation Science, 3(3), pp. 383-397.

Leonard-Barton, D. (1995). Wellsprings of Knowledge: Building and Sustaining the Sources of Innovation. Harvard Business School Press, Boston, MA.

Levinthal, D. (1997). 'Adaptation on Rugged Landscapes', Management Science, 43(7), pp. 934-950.

Levinthal, D. and J. March (1993). 'The Myopia of Learning', Strategic Management Journal, 14, pp. 95-112.

McNamara, P. (1998). 'British Biotech's Real Problem', Genetic Engineering News, 18(15), pp. 37 and 59.

McNamara, P. (1999). 'European Biotech Review: Despite Poor Performance, Celltech Shows the Way Forward', Genetic Engineering News, 19(4), pp. 20, 27 and 37.

McNamara, P., C. Baden-Fuller and J. Howell (1997). The Celltech Story: A Jewel in the Crown of the UK Biotechnology Sector. City University Business School case study.

Mahoney, J. (1995). 'The Management of Resources and the Resource of Management', Journal of Business Research, 33(2), pp. 91-101.

March, J. (1991). 'Exploration and Exploitation in Organisational Learning', Organisational Science, 2(1), pp. 71-87.

Markides, C. (1995). 'Diversification, Restructuring and Economic Performance', Strategic Management Journal, 16(2), pp. 101-118.

Miller, D. (1993). 'The Architecture of Simplicity', Academy of Management Review, 18(1), pp. 116-138.

Nonaka, I. (1994). 'A Dynamic Theory of Organisational Knowledge Creation', Organisation Science, 5(1), pp. 14-37.

Nonaka, I. and H. Takeuchi (1995). The Knowledge Creating Company. Oxford University Press, Oxford.

Orr, J. (1990). 'Sharing Knowledge, Celebrating Identity: Community Memory in a Service Culture'. In: D. Middleton and D. Edwards (eds), Collective Remembering, pp. 169-189. Sage, Newbury Park, CA.

Parexel International (1996). Pharmaceutical R\&D Statistical Sourcebook and Update 1996, reported in 'Study Cites Need for Technological Improvement in Clinical Trial Design', Genetic Engineering News, 17(7), pp. 33 and 46.

Pascale, R. (1990). Managing on the Edge. Viking, London.

Peteraf, M. (1993). 'The Cornerstones of Competitive Advantage', Strategic Management Journal, 14(3), pp. 179-191.

Pettigrew, A. and R. Whipp (1991). Managing Change for Competitive Success. Blackwell Business, Oxford.

Powell, W., K. Koput and L. Smith-Doerr (1996). 'Interorganisational Collaboration and the Locus of Innovation: Networks of Learning in Biotechnology', Administrative Science Quarterly, 41(1), pp. 116-145. 
Robbins, D. and D. Pearce II (1992). 'Turnaround: Recovery and Retrenchment', Strategic Management Journal, 13(4), pp. 287-309.

Silverman, D. (1993). Interpreting Qualitative Data. Sage, London.

Simon, H. (1991). 'Bounded Rationality and Organisational Learning', Organisation Science, 2, pp. 125-134.
Sutton, R. and B. Straw (1995). 'What Theory is Not', Administrative Science Quarterly, 40(3), pp. 371-384.

Whyte, W. (1984). Learning From the Field: A Guide from Experience. Sage, Beverly Hills, CA.

Yin, R. (1989). Case Study Research: Design and Methods. Sage, Newbury Park, CA. 